\title{
POSTERIOR BASIC (WALLED-OFF) MENINGITIS. REPORT OF A CASE WITH RECOVERY*
}

\author{
ABRAHAM SOPHIAN, M.D. \\ KANSAS CITY, MO.
}

Recovery after the development of "walled-off" meningitis is rare. Fisher ${ }^{1}$ reported the first case recovery in a child. Verbizer and Chauvel ${ }^{2}$ report recovery in an adult.

\section{REPORT OF CASE}

History.-A child, 11 months old, a patient of Dr. Saulberry, developed meningococcic meningitis. Serum treatment was begun late, two weeks after the onset, and was discontinued in the presence of a severe, persistent hydrocephalus, owing to objection by the parents. Four weeks after the onset the child presented the classical picture of "basic" meningitis; opisthotonos was marked, the eyes were wide open, staring, with lids retracted, the face expressionless. Hydrocephalus was extreme; head large, fontanel bulging, sutures widely separated. The heart's action was very irregular; respirations were irregular, of the Biot type. There was persistent tonic spasm of the extremities, with occasional clonic convulsions. Vomiting was repeated and projectile. The temperature reached $102 \mathrm{~F}$., and was of irregular type.

Diagnosis.LLumbar puncture at two levels yielded a few drops of clear, sterile cerebrospinal fluid. The clinical picture of hydrocephalus, meningeal irritation and absence of fluid in the subarachnoid space pointed to an encapsulated (walled-off) hydrocephalus, due to a closure of the foramina of Key, Retzius and Majendie.

Management.-Ventricular puncture was indicated. An ordinary lumbar puncture needle, with stylet attached, was introduced into the right ventricle through the extreme lateral border of the anterior fontanel. The needle was directed downward, backward and inward, and the ventricle was reached at a depth of about 2 inches. Fifty cubic centimeters of slightly turbid fluid under very high pressure were removed and 20 c.c. of serum injected. There was a fall of $10 \mathrm{~mm} . \mathrm{Hg}$ in blood pressure on the removal of the fluid, but no change on injecting the serum. The left ventricle was tapped the next day, 80 c.c. of turbid fluid removed and 20 c.c. of serum injected, with blood pressure change as on the previous day. The first fluid showed many pus cells and a few meningococci, extracellular and intracellular; the second specimen had only a few pus cells and intracellular organisms.

The right ventricle was tapped forty-eight hours later and 60 c.c. of clear fluid were removed. No meningococci were found. There was marked clinical improvement. The parents at this stage decided against any further intracerebral treatment. Improvement continued, however, and two weeks later the child had apparently recovered completely, with no obvious sequelae.

Subsequent Course.-Two months later the child presented a most unusual picture. He was bright, and had grown tremendously, having put on in two months the equivalent growth of a year and a half. He was active, playful,

* Submitted for publication April 14, 1917.

1. Fisher: New York Med. Jour., March 26, 1910.

2. Verbizer and Chauvel: Bull. et mém. Soc. méd. d. hôp. de Paris, 1916, 32. 
could see well, and had developed mentally almost in proportion to his skeletal growth. There was a large thymus. The head was large. During the previous month, however, the child had developed alarming spells of unconsciousness, marked cyanosis and dyspnea, lasting a few minutes; at first occurring every few days, then several times daily. I interpreted the condition as being due to a persistent hydrocephalus, and attributed the excessive skeletal development to pituitary involvement.

Lumbar puncture yielded 60 c.c. of clear sterile fluid under high pressure. The puncture proved that the communication between the ventricles and subarachnoid space had been reestablished. There were no convulsions for three days, and during the following two weeks convulsions occurred at infrequent intervals. Thyroid extract was administered.

A year later I learned that the child had grown very stout and large for his age, but was somewhat subnormal mentally. The attacks of cyanosis ceased a few months after the last puncture.

This case proved not only that recovery is possible, but that the communication between ventricles and subarachnoid space can be reestablished.

Various methods may be used to drain the ventricles. The simplest is puncture through the anterior fontanel, with or without drainage by tube or silk passing from without into the ventricles. ${ }^{3}$ When the fontanel is closed, Kocher's point for trephining over the anterior fontanel, or Keene's point for the posterior horn of the ventricle, may be selected. Haynes'4 cisternasinus drainage is intended to direct the cerebrospinal fluid into one of the brain sinuses. Sharp $\mathrm{p}^{5}$ describes the treatment of internal hydrocephalus by introducing linen strands into the ventricle and bringing the ends out through the temporal muscle and fascia, obtaining drainage in this way. Haynes' and Sharpe's methods are only applicable in that type of basic meningitis with sterile ventricular cerebrospinal fluid.

The most important requisites for successful results are early diagnosis and immediate intraventricular treatment. More important, however, is the prevention of this complication of simple epidemic meningitis. The secret is early diagnosis, early and persistent intraspinal serum treatment, and control of hydrocephalus.

Holmes and Twenty-Third Street.

3. Sophian, A.: Epidemic Meningitis, St. Louis, 1913.

4. Haynes: New York State Jour. Med., 1916, 16, 174.

5. Sharp: Am. Jour, Med. Sc., April, 1917. 